\title{
2 Cost-of-illness in patients with moderate to severe psoriasis: a cross-sectional survey in Hungarian dermatological centres
}

4 Orsolya Balogh • Valentin Brodszky • László Gulácsi • Emese Herédi •

5 Krisztina Herszényi - Hajnalka Jókai · Sarolta Kárpáti · Petra Baji •

6 Éva Remenyik · Andrea Szegedi · Péter Holló

Received: 10 February 2014/ Accepted: 31 March 2014

(C) Springer-Verlag Berlin Heidelberg 2014

\begin{abstract}
Background Despite the widespread availability of biological drugs in psoriasis, there is a shortage of disease burden studies.

Objectives To assess the cost-of-illness and quality of life of patients with moderate to severe psoriasis in Hungary.

Methods Consecutive patients with Psoriasis Area and Severity Index (PASI) > 10 and Dermatology Life Quality Index $(\mathrm{DLQI})>10$, or treated with traditional systemic (TST) or biological systemic treatment (BST) were included. Demographic data, clinical characteristics, psoriasis related medication, health care utilizations and employment status in the previous 12 months were recorded. Costing was performed from the societal perspective applying the human capital approach. Quality of life was assessed using DLQI and EQ-5D measures.

Results Two-hundred patients were involved (females $32 \%$ ) with a mean age of 51 (SD 13) years, 103 (52\%) patients were on BST. Mean PASI, DLQI and EQ-5D scores were 8 (SD 10), 6 (SD 7) and 0.69 (SD 0.3), respectively. The mean total cost was $€ 9,254 /$ patient/year
\end{abstract}

O. Balogh · V. Brodszky · L. Gulácsi $(\bowtie) \cdot$ P. Baji

Department of Health Economics, Corvinus University

of Budapest, Fővám tér 8, 1093 Budapest, Hungary

e-mail: laszlo.gulacsi@uni-corvinus.hu

E. Herédi · É. Remenyik · A. Szegedi

Department of Dermatology and Dermatological Allergology, University of Debrecen, Nagyerdei krt. 98., 4032 Debrecen,

Hungary

K. Herszényi · H. Jókai · S. Kárpáti · P. Holló

Department of Dermatovenereology and Oncodermatology,

Semmelweis University, Mária u. 41, 1085 Budapest, Hungary
(SD 8,502) with direct costs accounting for $86 \%$. The main cost driver was BST (mean €7,339/patient/year). Total costs differed significantly across treatment subgroups, mean (SD): no systemic therapy $€ 2,186(4,165)$, TST $€ 2,388(4,106)$ and BST $€ 15,790(6,016)(p<0,001)$. Patients with BST had better PASI and DLQI scores $(p<0.01)$ than the other two subgroups.

Conclusions Patients with biological treatment have a significantly better quality of life and higher total costs than patients with or without traditional systemic treatment. Our study is the largest in Europe and the first in the CEE region that provides cost-of-illness data in psoriasis involving patients with BST.

Keywords Psoriasis · Cost-of-illness · Quality of life · 45 Biological treatments

JEL Classification I190

Introduction

Psoriasis is a chronic inflammatory condition affecting about 0.73 to $2.9 \%$ of the population in Europe [1]. Skin disease with multiple different phenotypic variations and degrees of severity is the most prominent feature of psoriasis. Approximately $80 \%$ of patients with psoriasis have mild to moderate disease, whereas $20 \%$ have moderate to severe disease [2]. Classification of psoriasis severity takes into account not only the extent of body surface area involvement, but also the intensity of local signs and symptoms, history of previous treatments, disease duration, degree of disability and the impact of the disease on patients' quality of life [3]. Even a mild disease with limited extent can have a substantial psychological ( 7

\begin{tabular}{|l|lll|}
\hline & Journal : Large 10198 & Dispatch : $\mathbf{1 0 - 5 - 2 0 1 4}$ & Pages : 9 \\
Article No. : $\mathbf{5 9 9}$ & $\square$ & $\square$ TY & $\checkmark$ TYESET \\
& MS Code : Supplement14_Paper11 & $\sim_{\mathrm{CP}}$ & $\checkmark$ \\
\hline
\end{tabular}


impact on one's personal well-being [4]. Psoriasis is associated with considerable co-morbid conditions and elevated mortality has been observed in severe psoriasis $[5,6]$. Epidemiological studies suggest that about 5-25\% of patients with psoriasis also develop psoriatic arthritis (PsA) [7].

While commonly considered a non-life-threatening disease, psoriasis represents significant social and financial burden both for patients and the healthcare system. Owing to the persistent character of the disease patients with psoriasis usually need lifelong care which generates high continuing costs [8].

Highly effective and expensive biological therapies have increased interest in the cost-of-illness (COI) associated with psoriasis. A systematic literature review on the disease burden of moderate to severe psoriasis was published by Raho et al. [9] covering the period between 2002 and 2010. They found altogether seven COI studies from five countries (2 USA, 2 Germany, 1-1 Italy, Spain and Switzerland). Authors highlighted that patients' health related quality of life (HRQL) was affected by psoriasis to a degree comparable with diabetes or cancer. Treatment costs varied significantly across the studies. Direct costs were higher than indirect costs with hospitalization representing the most significant item. It is important to note, however, that there were no patient samples with biological treatment among the seven COI studies and none were from the Central and Eastern European (CEE) region.

The objective of our study was, therefore, to evaluate the disease burden of moderate to severe psoriasis in Hungary by assessing disease related costs from a societal perspective and patients' HRQL. Moreover, we updated the literature search for psoriasis COI studies in order to place our results in the context of the available publications. These data are required for health economic analyses and can provide a more complete picture to health care providers and policy makers on the economic implications of the disease.

Detailed analysis of HRQL related findings, including the mapping of EQ-5D utilities on disease-specific measures, are provided in another article in this supplement [10]. In this paper we present the main HRQL data and focus on COI results. Besides reporting summary results, we provide subgroup analyses in order to give an insight into the clinical and economic impact of different treatments. Thus, three subgroups were created after sampling based on patients' psoriasis treatment at the time of the survey: patients not receiving systemic therapy (NST); patients receiving traditional systemic treatment (TST) such as methotrexate, retinoids, cyclosporine or phototherapy; and patients on biological systemic treatment (BST), namely on adalimumab, etanercept, infliximab or ustekinumab.

\section{Methods}

Study design and patients

We conducted a non-interventional, cross-sectional questionnaire survey in two university dermatology clinics in Hungary. Patients with diagnosis of psoriasis, aged $\geq 18$ years and who gave informed consent were consecutively enrolled between September 2012 and May 2013. Inclusion criteria were set up considering disease severity (assessed by the Psoriasis Area and Severity Index, PASI), health related quality of life (assessed by the Dermatology Life Quality Index, DLQI) and treatment history [11]. (PASI and DLQI are introduced in the next section). Patients were eligible for inclusion with either 1) PASI $>10$ and DLQI > 10; or 2), traditional systemic treatment (TST) or biological systemic treatment (BST) at the time of the survey. Ethical approval was obtained from the national ethical committee (ETT-TUKEB 35183/2012-EKU).

Survey

Patients completed a set of questions in which demographic data, employment status, disease duration, selfassessed disease activity on a visual analogue scale (VAS) and psoriasis related topical treatments were surveyed. Psoriasis related outpatient care utilizations (GP and dermatologist visits in the past one and three months, respectively), hospitalizations and transportation to attend medical care in the previous 12 months were recorded. Informal care was assessed for the past month (the number of hours per week provided by others to help the patient in his/her everyday activities). Patients were asked to indicate co-payments and full out-of-pocket expenditures as well.

Absence from work and reduced work productivity were captured by the Work Productivity and Activity Impairment questionnaire (WPAI) [12].

A validated Hungarian version of the Dermatology Life Quality Index (DLQI) was used to assess disease-specific quality of life. The DLQI ranges between 0 (not affected) to 30 (extremely affected), the higher scores correspond to a more impaired quality of life [13].

As a generic health status measure, the EQ-5D questionnaire was used which comprises a descriptive system (EQ5D-3L) and a Visual Analogue Scale (EQ VAS). The responses to the EQ-5D-3L were converted to utility scores (ranging from -0.594 to 1.0) using the UK social tariffs [14].

Participating dermatologists assessed disease activity on a VAS and disease severity by the Psoriasis Area and Severity Index (PASI) [15]. The PASI combines assessments of the extent of body surface involvement in four anatomical regions (head, trunk, arms and legs) and the severity of desquamation, erythema and plaque induration

\begin{tabular}{|l|lll|}
\hline Journal : Large 10198 & Dispatch : 10-5-2014 & Pages : 9 \\
Article No. : 599 & $\square$ & LE & $\square$ TYPESET \\
MS Code : Supplement14_Paper11 & $\sim_{\text {CP }}$ & $\checkmark$ DISK \\
\hline
\end{tabular}


(thickness) in each region, yielding an overall score from 0 to 72 . The PASI is part of most currently used classifications of disease severity in psoriasis and represents a necessary first step in selecting a treatment strategy. Moderate to severe disease is defined as a PASI score $>10$ [15]. Dermatologists categorized patients by the clinical features of psoriasis and provided data on current and previous systemic treatments (both traditional and biological systemic treatments in the past 12 months).

\section{Costs calculation}

Data obtained from the questionnaire survey were used for the calculation of psoriasis related costs. Cost calculation was performed from a societal perspective (including direct medical, direct non-medical and indirect costs) over a 12 -months period. Hungarian official prices and tariffs were used and costs were presented in 2012 EUR rate $(€ 1=285$ HUF). The cost of outpatient care was calculated by multiplying the number of visits by the estimated unit prices (GP: $€ 5.2 /$ visit, specialist: $€ 5.7 /$ visit) $[16,17]$. Cost of hospitalization was based on Disease Related Groups (DRGs) reimbursement list (€373.7/admission) [18]. Drug costs were calculated based on official national prices of pharmaceuticals [17]. Travel cost to attend health care due to psoriasis was calculated considering the number of visits, the mode of transportation used and the distance between the patient's residence and the dermatology centre [19, 20]. In cases of ambulance transportation unit costs per $\mathrm{km}(€ 3.1 / \mathrm{km})$ was applied based on official financing data [21]. Weekly cost of informal care was estimated by multiplying the average hourly net wage in Hungary ( $€ 3$ /hour) [16] with the number of hours per week, but it was capped at a maximum of $40 \mathrm{~h} /$ week. The costs of absence from work and disability pension due to psoriasis were calculated using both Human Capital
Approach (HCA) [22] and Friction Cost Approach (FCA) [23] with six-month friction period. Average gross income (€1,054/month in 2012, including net wage, personal income tax, pension contribution, health insurance contributions, employer's contribution) was used to estimate daily cost ( $€ 50 /$ day) of productivity loss which was multiplied with the number of days of absence [16].

Statistical analysis

Statistical analysis of the data was carried out using SPSS Version 20.0 for Windows. Descriptive statistics were performed and analyses focused on the comparison between treatment subgroups (NST, TST, and BST). We present the mean with standard deviation, median and bootstrap confidence intervals (1,000 drawings) for each cost domain. Due to the skewed distribution of the cost data, subgroups were compared by non-parametric tests. The level of significance was set to 0.05 .

\section{Results}

Socio-demographic and clinical characteristics

Altogether 200 patients completed the questionnaire, $68 \%$ were male. The mean age of the patients was 51 years (SD 13) and the disease duration was 22 years (SD 11). Main characteristics of the patients are presented in Table 1. The distance between the patient's home and the dermatology centre was mean 51 (SD 57) km. Altogether 99 (50\%) patients were working (fulltime 79, part time 20) at the time of the assessment, $16(8 \%)$ were on disability pension due to psoriasis. Regarding the characteristics of subgroups, patients receiving biological drug (BST subgroup) were significantly younger
Table 1 Main characteristics of the patients

NST no systemic treatment, TST traditional systemic treatment, $B S T$ biological systemic treatment

\begin{tabular}{lcccc}
\hline Variables & $\begin{array}{l}\text { All patients } \\
N=200 ; \\
\text { mean (SD) }\end{array}$ & $\begin{array}{l}\text { NST } N=36 ; \\
\text { mean (SD) }\end{array}$ & $\begin{array}{l}\text { TST } N=61 ; \\
\text { mean (SD) }\end{array}$ & $\begin{array}{l}\text { BST } N=103 ; \\
\text { mean (SD) }\end{array}$ \\
\hline Descriptive statistics & & & & \\
Females $N(\%)$ & $63(32)$ & $11(31)$ & $21(34)$ & $31(30)$ \\
Age (year) & $51(13)$ & $56(13)$ & $52(13)$ & $49(12)$ \\
Disease duration (year) & $22(11)$ & $18(11)$ & $23(12)$ & $23(11)$ \\
Weight (kg) & $88(18)$ & $83(15)$ & $86(20)$ & $91(18)$ \\
Height (cm) & $172(9)$ & $171(9)$ & $170(10)$ & $172(9)$ \\
Body Mass Index (BMI) & $29.85(5)$ & $28.38(6)$ & $29.75(5)$ & $29.55(5)$ \\
Disease related variables & & & & \\
PASI index & $8(10)$ & $18(11)$ & $11(10)$ & $2(5)$ \\
DLQI score & $6(7)$ & $12(6)$ & $10(8)$ & $2(4)$ \\
EQ VAS & $64(21)$ & $55(20)$ & $59(17)$ & $70(22)$ \\
EQ-5D score (-0.594-1) & $0.69(0.3)$ & $0.65(0.3)$ & $0.62(0.3)$ & $0.75(0.3)$ \\
Self-assessed disease activity VAS (0-100 mm) & $35(33)$ & $60(30)$ & $49(31)$ & $18(25)$ \\
Physician's global assessment VAS (0-100 mm) & $23(28)$ & $58(24)$ & $34(28)$ & $7(14)$ \\
\hline
\end{tabular}

\begin{tabular}{|l|lll|}
\hline & Journal : Large 10198 & Dispatch : 10-5-2014 & Pages : 9 \\
Article No. : $\mathbf{5 9 9}$ & $\square$ LE & $\square$ TYPESET \\
& MS Code : Supplement14_Paper11 & $\sim_{\text {CP }}$ & $\checkmark$ DISK \\
\hline
\end{tabular}


Table 2 Annual utilization of health care services, drugs and productivity loss

\begin{tabular}{|c|c|c|c|c|c|c|c|c|}
\hline \multirow[t]{2}{*}{ Health care services } & \multicolumn{2}{|c|}{ Total sample $N=200$} & \multicolumn{2}{|c|}{ NST $N=36$} & \multicolumn{2}{|c|}{ TST $N=61$} & \multicolumn{2}{|c|}{ BST $N=103$} \\
\hline & $N(\%)$ & $\begin{array}{l}\text { Utilization, } \\
\text { mean } \\
\text { (events/days) }\end{array}$ & $N(\%)$ & $\begin{array}{l}\text { Utilization, } \\
\text { mean } \\
\text { (events/days) }\end{array}$ & $N(\%)$ & $\begin{array}{l}\text { Utilization, } \\
\text { mean } \\
\text { (events/days) }\end{array}$ & $N(\%)$ & $\begin{array}{l}\text { Utilization, } \\
\text { mean } \\
\text { (events/days) }\end{array}$ \\
\hline \multicolumn{9}{|l|}{ Physician visits $^{\mathrm{a}}$} \\
\hline GP visits & $49(25)$ & 4.3 & $12(33)$ & 6.6 & $26(43)$ & 7.5 & $11(11)$ & 1.5 \\
\hline Dermatology specialist visit & $159(80)$ & 6.3 & $24(67)$ & 9.5 & $49(80)$ & 7.6 & $86(84)$ & 4.5 \\
\hline Dermatological inpatient care & $57(29)$ & 0.4 & $11(31)$ & 0.4 & $32(53)$ & 0.6 & $14(14)$ & 0.2 \\
\hline \multicolumn{9}{|l|}{ Transportation $^{\mathrm{a}}$} \\
\hline Ambulance & $10(5)$ & 0.2 & - & - & $3(5)$ & 0.4 & 7 (7) & 0.3 \\
\hline Travel voucher & $28(14)$ & 0.6 & $1(3)$ & 0.05 & $9(15)$ & 0.5 & $18(18)$ & 0.8 \\
\hline Travel cost & $172(86)$ & 1.7 & $35(97)$ & 2.6 & $52(85)$ & 2.3 & $85(83)$ & 1 \\
\hline \multicolumn{9}{|l|}{ Productivity loss ${ }^{\mathrm{b}}$} \\
\hline Sick leave & $18(9)$ & 2 & $4(11)$ & 1.4 & $8(13)$ & 3.6 & $6(6)$ & 1.3 \\
\hline Disability due to psoriasis & $16(8)$ & 29 & $3(8)$ & 30 & $2(3)$ & 12 & $11(11)$ & 39 \\
\hline \multicolumn{9}{|l|}{ Pharmacotherapy ${ }^{\mathrm{c}}$} \\
\hline \multicolumn{9}{|l|}{ TST } \\
\hline Methotrexate & $86(43)$ & 226 & 7 (19) & 136 & $38(62)$ & 216 & $41(40)$ & 252 \\
\hline Retinoids & $22(11)$ & 151 & $4(11)$ & 151 & $16(26)$ & 164 & $2(2)$ & 47 \\
\hline Cyclosporin & $16(8)$ & 189 & $3(1)$ & 233 & $10(16)$ & 223 & $3(3)$ & 30 \\
\hline Phototherapy & $7(4)$ & 77 & $2(1)$ & 188 & $5(8)$ & 32 & - & - \\
\hline \multicolumn{9}{|l|}{$B S T$} \\
\hline Etanercept & $18(9)$ & 293 & - & - & - & - & $18(17)$ & 293 \\
\hline Infliximab & $42(21)$ & 319 & - & - & - & - & $42(40)$ & 319 \\
\hline Adalimumab & $35(18)$ & 300 & - & - & $1(2)$ & 21 & $34(33)$ & 308 \\
\hline Ustekinumab & $17(9)$ & 260 & - & - & $1(2)$ & 176 & $16(16)$ & 265 \\
\hline
\end{tabular}

a Utilization of health care services for the total group

b The length of absence or disability (days)

c Drug utilization among active users of the given medication in the past 12 months (days of treatment)

than patients without systemic treatment (NST) and moreover, disease duration of patients receiving systemic treatment (BST and TST subgroups) had a significantly longer disease duration than NST patients $(p<0.05)$.

Health care utilizations due to psoriasis

Health care utilizations, medications and productivity loss are presented in Table 2. Altogether 105 patients $(53 \%)$ have had biological treatment in the past 12 months and seven switches occurred between diverse biological agents whilst two patients stopped biological treatment. Thus, altogether 103 patients ( $52 \%$ ) were on biological treatment at the time of the survey, and they were considered for the BST subgroup. Thirty-six (18\%) patients were in the NST subgroup and 61 patients (30\%) were receiving TST.

Psoriasis related costs

The annual costs of all psoriasis related items are presented in Table 3. The mean annual total cost per patient with HCA and FCA was $€ 9,254$ (SD €8,502) and $€ 8,305$ (SD $€ 7,705$ ), respectively, with direct costs accounting for 86 and $96 \%$. The main cost driver was the biological drug cost amounting to mean $€ 7,339 /$ patient/year in the total sample $(N=200)$. Average total cost differed significantly between treatment subgroups (NST, TST and BST) both with HCA and FCA $(p<0.001)$ (Table 3).

Disease severity and quality of life across treatment subgroups

Disease severity (PASI) differed significantly across the three subgroups as patients without systemic treatment (NST) were in the worst state whilst those on biological drug (BST) in the best state $(p<0.01)$. HRQL (assessed by the DLQI) of patients with biological treatment was significantly better compared to the other two subgroups $(p<0.01)$. The difference in health status utility (EQ-5D score) was significant only between BST and TST subgroups $(p<0.01)($ Table 1$)$.
243

244

245

246

247

248

249

250

253

254

255

256

257

258

259

260

261

\begin{tabular}{|l|lll|}
\hline & Journal : Large 10198 & Dispatch : 10-5-2014 & Pages : 9 \\
& Article No. : $\mathbf{5 9 9}$ & $\square$ & \\
MS Code : Supplement14_Paper11 & $\checkmark_{\mathrm{CP}}^{\text {LE }}$ & $\square$ TYPESET \\
\hline
\end{tabular}




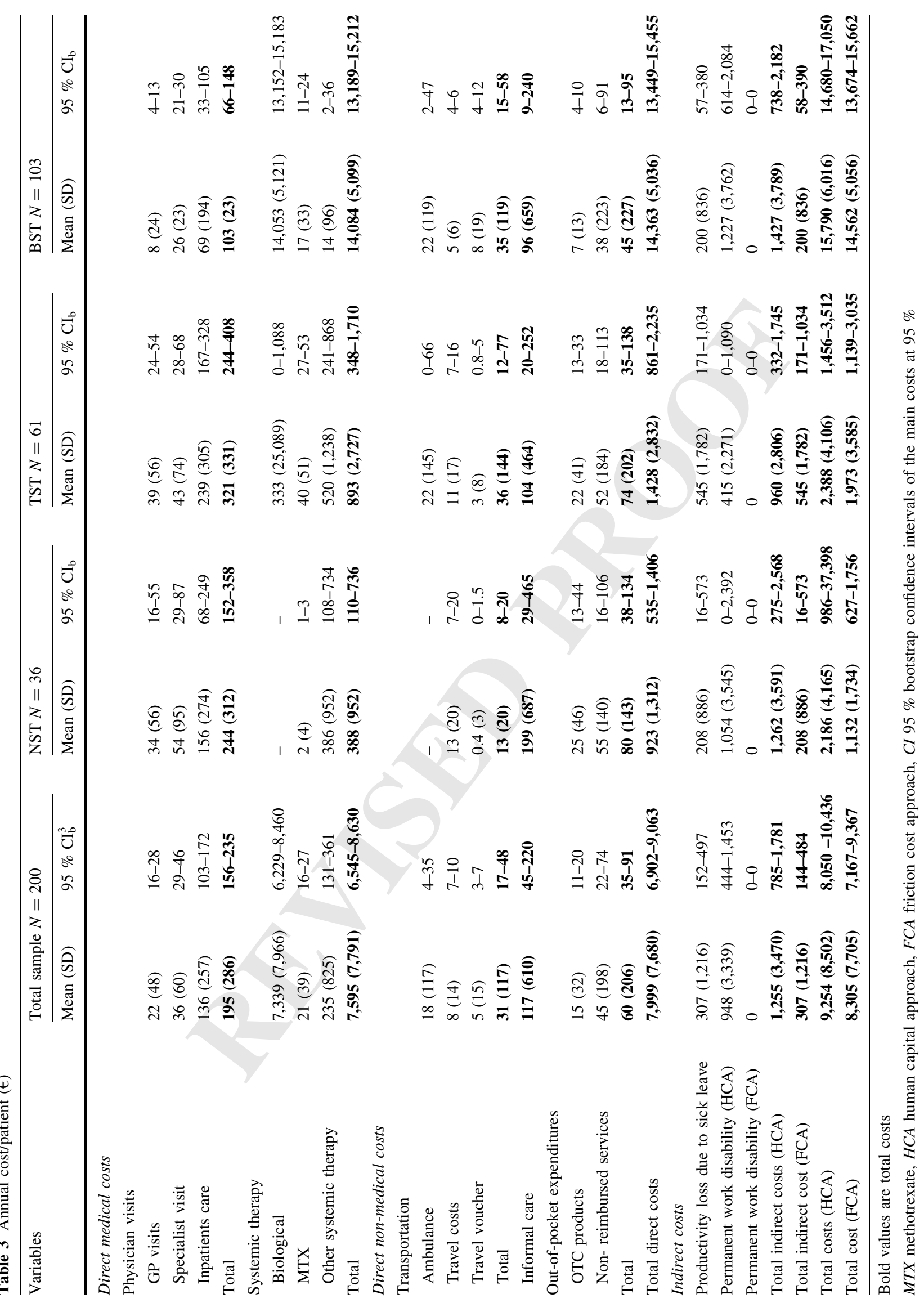

\begin{tabular}{|l|lll|}
\hline & Journal : Large 10198 & Dispatch : $\mathbf{1 0 - 5 - 2 0 1 4}$ & Pages : 9 \\
Article No. : $\mathbf{5 9 9}$ & $\square$ LE & $\square$ TYPESET \\
& MS Code : Supplement14_Paper11 & $\boldsymbol{\sim}_{\mathrm{CP}}$ & $\boldsymbol{\sim}_{\text {DISK }}$ \\
\hline
\end{tabular}




\section{Discussion}

263

264

265

266

267

268

269

270

271

272

273

274

275

276

277

278

279

280

281

282

283

284

285

286

287

288

289

290

291

292

293

294

295

296

297

298

299

300

301

302

303

304

305

306

307

308

309

310

311

312

313
This study provides data on COI and HRQL in patients with moderate to severe psoriasis in Hungary attending hospital based dermatology centres. The annual societal cost of psoriasis in patients with a mean age of 50 years and a disease duration since first medical diagnosis of psoriasis of 22 years is mean $€ 9,254$ per patient, and is primarily driven ( $86 \%$ ) by direct medical costs.

The majority of the patients $(N=103,52 \%)$ were receiving a biological agent at the time of the assessment. According to the latest available data of National Health Insurance Fund Administration, in 2010 altogether 682 patients with psoriasis received biological treatment in Hungary thus our survey captured a substantial proportion of this patient group [24]. Analysis by treatment subgroups revealed that yearly average total costs differ significantly across NST $(€ 2,186)$, TST $(€ 2,388)$ and BST $(€ 15,790)$ subsamples.

Significant differences were observed across treatment subgroups with regard to disease severity (PASI, DLQI) and patients' general health state (EQ-5D) as well (Table 1). Patients with biological treatment had a significantly lower disease severity (PASI score) and better HRQL (DLQI score) than their counterparts with or without traditional systemic treatment. The EQ-5D indicated also the best health state in the BST subgroup, however, the difference was significant only compared to the TST subgroup. When comparing EQ-5D utility weights to the agematched population norm in Hungary (age group 45-54 years, mean 0.81) [25] a lower average score was observed in each subgroup (NST: 0.65, TST: 0.62, and BST: 0.75) resulting in a difference of 0.16, 0.19 and 0.6, respectively.

Both the average direct medical cost (excluding biological treatment costs) and indirect cost were the lowest in the BST subgroup when applying the 6-month FCA (Table 3). One reason for that is the rate of patients who went on sick leave due to psoriasis in the past 12 months was the lowest (6\%) among the subgroup of patients with biological treatment (Table 2). On the other hand, although the rate of disability pensioners was the highest in this same subsample $(11 \%)$, all of them were classified as permanently unable to work before the time period considered for the friction cost calculation. As a consequence, when HCA was used to calculate productivity related costs, the BST subgroup ranked as the one with the highest indirect cost. Overall we can conclude that patients on biological treatment had the highest total costs but the lowest disease activity and best quality of life compared to their counterparts receiving conventional systemic treatment or no systemic treatment.

Presence of psoriatic arthritis (PsA) may represent additional burden in psoriasis although findings in the literature are contradictory [26]. In our study 57 patients (29\%) were diagnosed with PsA (females $35 \%$, mean age 54 years, psoriasis disease duration 23 years) and $52 \%$ of them received biological therapy. The mean EQ-5D score of patients with concomitant PsA was significantly lower $(<0.01)$ than that of patients without PsA, nevertheless they were older as well (54 vs. 51 years, $p=0.035$ ). Cost of informal care was high (mean €314/patient/year) among PsA patients reflecting a high disability and dependence on others of this specific subsample. Mean annual cost (with HCA) of patients with PsA was $€ 8,977$ (SD 9,488) per patient and total costs by NST, TST and BST subgroups were mean $€ 1,729, € 775$ and $€ 16,983$, respectively. For comparison, Brodszky and colleagues surveyed 183 patients with PsA in Hungary in 2007 with similar age (mean 50 years) and disease duration (mean 19 years) [27]. The rate of patients on biological treatment was much lower $(6 \%)$ resulting in a somewhat lower total cost (mean $€ 5,547 /$ patient/year, on 2007 prices). Nevertheless, when patients on biological treatment were excluded from the analysis total cost were much higher (mean $€ 4,281 /$ patient/ year, on 2007 prices) than in the NST and TST subgroups of PsA patients in our current survey. These results seem to suggest that rheumatic features might add extra HRQL loss and increase in costs in psoriasis. Nonetheless, further direct comparative studies are needed to confirm our findings.

Taking into account that the first biological agent was registered for the treatment of psoriasis in 2004, we would have expected COI studies involving patients with biological treatment by the end of January 2010, the date when the last systematic literature review was closed [9]. Contrarily, no such studies had been published by that time. Therefore, we performed a literature search for COI studies for the period from January 2010 to December 2013 using the same search terms and databases as Raho et al. [9].Our search identified a further nine publications [28-36], seven of which involved psoriasis patients with biological treatment. In the COI analyses conducted by Fonia et al. (UK) [28] and Driessen et al. (the Netherlands) [29] all patients were treated with biological drugs. The biological treatment rate was $16 \%$ in the study by Ghatnekar et al. (Sweden) [34], $13 \%$ by Levy and colleagues (Canada) [33], $6 \%$ by Steinke et al. (Germany) [36] and $3.6 \%$ by Le Moigne et al. (France) [32]. Only one study by Gleason and colleagues (US) did not report the rate of biological therapy [31].

Studies that provided costs specifically for BST groups or subgroups were selected for comparison. Neither the study by Gleason et al. (US) [31] nor the one by Levy et al. (Canada) [33] reported costs data for BST group, therefore, these were excluded. Moreover, only eight patients received biological agent in the study by Steinke et al. [36] 
Table 4 Cost-of-illness studies of psoriasis, reporting costs of BST, till December 2013 in comparison with results of the current survey

\begin{tabular}{|c|c|c|c|c|c|c|}
\hline Study & Method & Patients & $\begin{array}{l}N_{\text {total }} / \\
N_{\text {biologic }}\end{array}$ & $\begin{array}{l}\text { Mean direct } \\
\text { cost/patient/ } \\
\text { year TST/BST }\end{array}$ & $\begin{array}{l}\text { Mean indirect } \\
\text { cost/patient/year } \\
\text { TST/BST }\end{array}$ & $\begin{array}{l}\text { Mean total } \\
\text { cost/patient/ } \\
\text { year TST/BST }\end{array}$ \\
\hline $\begin{array}{l}\text { Fonia et al. } \\
\text { [28], United } \\
\text { Kingdom }\end{array}$ & $\begin{array}{l}\text { Retrospective } \\
\text { chart review }\end{array}$ & $\begin{array}{l}\text { Severe psoriasis, } 2 \text { tertiary dermatology } \\
\text { centers }\end{array}$ & $76 / 76$ & $\begin{array}{l}€ 4,742 / \\
€ 13,505\end{array}$ & n.r. & n.a. \\
\hline $\begin{array}{l}\text { Driessen et al. } \\
\text { [29], The } \\
\text { Netherlands }\end{array}$ & $\begin{array}{l}\text { Retrospective } \\
\text { chart review }\end{array}$ & $\begin{array}{l}\text { Moderate to severe psoriasis, } 1 \text { tertiary } \\
\text { dermatology center }\end{array}$ & $67 / 67$ & $\begin{array}{l}€ 10,146 / \\
€ 17,712\end{array}$ & n.r. & n.a. \\
\hline $\begin{array}{l}\text { Ghatnekar et al. } \\
\text { [34], Sweden }\end{array}$ & $\begin{array}{l}\text { Follow-up } \\
\text { study }\end{array}$ & $\begin{array}{l}\text { Severe psoriasis, } 1 \text { tertiary and } 1 \text { secondary } \\
\text { dermatology center }\end{array}$ & $164 / 27$ & $\begin{array}{l}€ 7,812 / \\
€ 18,457\end{array}$ & $€ 5,208 / € 2,051$ & $\begin{array}{l}€ 13,020 / \\
€ 20,508\end{array}$ \\
\hline $\begin{array}{l}\text { Le Moigne et al. } \\
\text { [32], France }\end{array}$ & $\begin{array}{l}\text { Insurance } \\
\text { claim } \\
\text { database } \\
\text { analysis }\end{array}$ & $\begin{array}{l}\text { General psoriasis population, all types of } \\
\text { out-patient and inpatient providers in an } \\
\text { administrative area }\end{array}$ & $\begin{array}{c}1,924 / \\
69\end{array}$ & $\begin{array}{l}€ 3,356 / \\
€ 16,214\end{array}$ & & n.a. \\
\hline $\begin{array}{l}\text { Our study } \\
\text { (2014) }\end{array}$ & $\begin{array}{l}\text { Cross- } \\
\text { sectional } \\
\text { study }\end{array}$ & $\begin{array}{l}\text { Moderate to severe psoriasis at } 2 \text { tertiary } \\
\text { dermatology centers }\end{array}$ & $\begin{array}{c}200 / \\
103\end{array}$ & $\begin{array}{l}€ 1,428 / \\
€ 14,363\end{array}$ & $€ 960 / € 1,427$ & $\begin{array}{l}€ 2,388 / \\
€ 15,790\end{array}$ \\
\hline
\end{tabular}

n.r. not reported, n.a. not applicable

Levy and colleagues did not report costs of BST population, Steinke and colleagues reported costs of BST population, however, the sample size of the patients treated with biologicals were low $(N=8)$, not big enough for comparison

(Germany) so this was not considered either. Finally we compared our results to four studies: Fonia (UK, 2010) [28], Driessen (the Netherlands, 2010) [29], Ghatnekar (Sweden, 2012) [34] and Le Moigne (France, 2013) [32] (Table 4).

Fonia et al. [28] conducted a retrospective chart review involving 76 BST patients. Health care resource utilization data were collected 12 months before and after BST initiation. The viewpoint of cost calculation was the third party payer and only direct medical costs were collected. Total cost of psoriasis care prior to biological treatment was $£ 4,207 /$ patient/year $(€ 4,742)$ while after the biological treatment was initiated total costs rose to $£ 11,981$ /patient/ year $(€ 13,505)$. The cost of the biological treatment was the main cost driver. However the total cost of hospitalization decreased by $£ 1,683 /$ patient/year $(€ 1,897)$ and PASI decreased by 8.9 points in the BST subgroup.

A similar study design was applied in the Netherlands. Driessen et al. [29] collected health care resource utilization data 12 months before and after starting biologic therapy start based on retrospective chart review including 67 BST patients. Mean direct medical cost during the pre and post period was $€ 10,146$ and $€ 17,712 /$ patient/year, respectively. The costs of other drug treatments, outpatient visits and hospitalizations decreased during the year after the biological therapy was given. An improvement of skin manifestation was observed after BST initiation and PASI decreased by 12.6 points.
A retrospective health insurance claims database analysis was conducted by Le Moigne et al. [32] among patients with moderate to severe psoriasis in France. Two cohorts of $69 \mathrm{BST}$ and 1,855 TST patients were compared during a 6-month period. The mean total direct medical costs in BST and TST patient groups were $€ 16,214$ vs. $€ 3,356 /$ patient/year. All cost items were higher in the BST subgroup and the largest difference was identified in the cost of hospitalization, as this cost item was €886/patient/ year higher than in TST subgroup.

In Sweden, Ghatnekar et al. [34] performed a 1-month prospective study in 2009 from the societal viewpoint. Altogether 164 patients were involved and among them 27 (16\%) patients received BST. For the whole study population the average total cost was $€ 11,928 /$ patient/year (when monthly costs are multiplied by 12) which is higher than in our study (€9,254/patient/year). The total cost of TST subgroup was $€ 13,020 /$ patient/year, which is much higher than our TST result ( $€ 2,388 /$ patient/year).

The main direct cost drivers were the biological drugs, outpatient visits and phototherapy. The indirect cost (productivity loss) was $16 \%$ of the total costs, which is similar to our finding of $14 \%$ associated with indirect costs. In the BST subgroup the yearly average total costs were $€ 20,508$ whilst we reported $€ 15,790$ per patient in our study. The indirect costs were lower in BST than in the TST subgroup ( $€ 2,051$ vs. $€ 5,208)$. Despite the $€ 14,280 /$ patient/year difference of drug costs for TST vs. BST, the difference in

\begin{tabular}{|c|c|c|c|}
\hline Journal : Large 10198 & Dispatch & $10-5-2014$ & Pages : \\
\hline $\begin{array}{l}\text { Article No. : } 599 \\
\text { MS Code : Supplement14_Paper11 }\end{array}$ & $\begin{array}{ll}\square & \mathrm{LE} \\
\boldsymbol{C P}^{2}\end{array}$ & & $\begin{array}{l}\square \text { TYPESET } \\
\boldsymbol{D} \\
\text { DISK }\end{array}$ \\
\hline
\end{tabular}


total cost between these two subgroups was only $€ 7,476 /$ patient/year due to the offsets from improved productivity. In our study the indirect cost of BST subgroup was higher (HCA) than in TST subgroup (€1,427 vs. €960).

The total costs of BST presented in three of the four studies $[29,32,34]$ were higher compared to our results in Hungary. In three studies [28, 29, 32] the costs of hospitalization and out-patient visits were lower in BST subgroup, similarly to our findings. These studies were conducted in tertiary dermatology centres with a very similar methodology. Le Moigne et al. [32] presented different results. In this study the cost of out-patient visit and hospitalization was higher in the BST subgroup compared to other subgroups. Health care utilization data are greater depending on the financing mechanisms, professional and financing guidelines, management, standard care, referral system, unit costs and cost accounting approaches of the given country and vary substantially, so it is very difficult to make comparisons among countries.

Our study has some limitations. The survey was conducted in two university based dermatology centres involving psoriasis patients attending outpatient care. Patients with mild psoriasis were not selected and patients with severe psoriasis might be under-represented in the sample. We used a retrospective survey to assess health care utilizations, recall bias might occur. Another limitation is due to the cross-sectional design, the current treatment were used as a proxy to measure disease severity and costs. In this sample there is a mixed patient population in terms of severity of disease, patients with recently initiated or changed treatment where the full effect has not been achieved yet. Seasonal variations were not taken into consideration. Further research is needed involving representative samples and incidence follow-up cohorts to further assess the changes in costs and in quality of life in the long term.

Our study showed that the economic burden of psoriasis is considerable in Hungary and revealed that results from health economic studies in psoriasis in other countries cannot be adapted without adjustment. With this study we provided input for further health economic analyses and a baseline to evaluate the economic effects of psoriasis treatment in Hungary. In line with our hypothesis, biological treatment increased the direct costs associated with psoriasis while considerably improving the quality of life of patients. Our study was the first from the CEE region that provided COI data and had the largest sample size of biologic treated patients in Europe.

Acknowledgments The authors are grateful to patients participating in the survey. Proofreading of the manuscript was supported by the TÁMOP 4.2.2./B-10/1-2010-0023 project.

\section{References}

1. Parisi, R., Symmons, D.P., Griffiths, C.E., Ashcroft, D.M.: Global epidemiology of psoriasis: a systematic review of incidence and prevalence. J. Invest. Dermatol. 133(2), 377-385 (2013). doi:10. 1038/jid.2012.339

2. Menter, A., Korman, N.J., Elmets, C.A., Feldman, S.R., Gelfand, J.M., Gordon, K.B., Gottlieb, A., Koo, J.Y., Lebwohl, M., Lim, H.W., Van Voorhees, A.S., Beutner, K.R., Bhushan, R.: Guidelines of care for the management of psoriasis and psoriatic arthritis. Section 3. Guidelines of care for the management and treatment of psoriasis with topical therapies. J. Am. Acad. Dermatol. 60(4), 643-659 (2009). doi:10.1016/j.jaad.2008.12.032

3. EMA, C.f.M.P.f.H.U.: Guideline on clinical investigation of medicinal products indicated for the treatment of psoriasis. http:// www.ema.europa.eu/docs/en_GB/document_library/Scientific_ guideline/2009/09/WC500003329.pdf (2004)

4. Menter, A., Korman, N.J., Elmets, C.A., Feldman, S.R., Gelfand, J.M., Gordon, K.B., Gottlieb, A., Koo, J.Y., Lebwohl, M., Leonardi, C.L., Lim, H.W., Van Voorhees, A.S., Beutner, K.R., Ryan, C., Bhushan, R.: Guidelines of care for the management of psoriasis and psoriatic arthritis: section 6. Guidelines of care for the treatment of psoriasis and psoriatic arthritis: case-based presentations and evidence-based conclusions. J. Am. Acad. Dermatol. 65(1), 137-174 (2011). doi:10.1016/j.jaad.2010.11.055

5. Richard, M.A., Barnetche, T., Horreau, C., Brenaut, E., Pouplard, C., Aractingi, S., Aubin, F., Cribier, B., Joly, P., Jullien, D., Le Maitre, M., Misery, L., Ortonne, J.P., Paul, C.: Psoriasis, cardiovascular events, cancer risk and alcohol use: evidence-based recommendations based on systematic review and expert opinion. J. Eur. Acad. Dermatol. Venereol. 27(Suppl 3), 2-11 (2013). doi: $10.1111 / j d v .12162$

6. Ogdie, A., Haynes, K., Troxel, A.B., Love, T.J., Hennessy, S., Choi, H., Gelfand, J.M.: Risk of mortality in patients with psoriatic arthritis, rheumatoid arthritis and psoriasis: a longitudinal cohort study. Ann. Rheum. Dis. 73(1), 149-153 (2014). doi:10. 1136/annrheumdis-2012-202424

7. Dhir, V., Aggarwal, A.: Psoriatic arthritis: a critical review. Clin. Rev. Allergy Immunol. 44(2), 141-148 (2013). doi:10.1007/ s12016-012-8302-6

8. Radtke, M.A., Augustin, M.: Economic considerations in psoriasis management. Clin. Dermatol. 26(5), 424-431 (2008). doi:10. 1016/j.clindermatol.2007.10.024

9. Raho, G., Koleva, D.M., Garattini, L., Naldi, L.: The burden of moderate to severe psoriasis: an overview. Pharmacoeconomics 30(11), 1005-1013 (2012). doi:10.2165/11591580-00000000000000

10. Herédi, E., Rencz, F., Balogh, O., Gulácsi, L., Herszényi, K., Holló, P., Jókai, H., Kárpáti, S., Péntek, M., Remenyik, É., Szegedi, A., Brodszky, V.: Exploring the relationship between EQ-5D, DLQI and PASI, and mapping EQ-5D utilities: a crosssectional study in psoriasis from Hungary. The European Journal of Health Economics (in press) (2014)

11. Finlay, A.Y.: Current severe psoriasis and the rule of tens. Br. J. Dermatol. 152(5), 861-867 (2005). doi:10.1111/j.1365-2133. 2005.06502.x

12. Reilly, M.C., Zbrozek, A.S., Dukes, E.M.: The validity and reproducibility of a work productivity and activity impairment instrument. Pharmacoeconomics 4(5), 353-365 (1993)

13. Finlay, A.Y., Khan, G.K.: Dermatology Life Quality Index (DLQI) - a simple practical measure for routine clinical use. Clin. Exp. Dermatol. 19(3), 210-216 (1994)

14. Kind, P., Dolan, P., Gudex, C., Williams, A.: Variations in population health status: results from a United Kingdom national questionnaire survey. BMJ 316(7133), 736-741 (1998) 
15. Pathirana, D., Ormerod, A.D., Saiag, P., Smith, C., Spuls, P.I., Nast, A., Barker, J., Bos, J.D., Burmester, G.R., Chimenti, S., Dubertret, L., Eberlein, B., Erdmann, R., Ferguson, J., Girolomoni, G., Gisondi, P., Giunta, A., Griffiths, C., Honigsmann, H., Hussain, M., Jobling, R., Karvonen, S.L., Kemeny, L., Kopp, I., Leonardi, C., Maccarone, M., Menter, A., Mrowietz, U., Naldi, L., Nijsten, T., Ortonne, J.P., Orzechowski, H.D., Rantanen, T., Reich, K., Reytan, N., Richards, H., Thio, H.B., van de Kerkhof, P., Rzany, B.: European S3-guidelines on the systemic treatment of psoriasis vulgaris. J. Eur. Acad. Dermatol. Venereol. 23(Suppl 2), 1-70 (2009). doi:10.1111/j.1468-3083.2009.03389.x

16. Hungarian Central Statistical Office: Gross wages and salaries (2001-2012). http://www.ksh.hu/docs/hun/eurostat_tablak/tabl/ tec00014.html (2012). Accessed 1 September 2013

17. National Health Insurance Fund Administration: Official list of drugs (2012). Accessed 1 Sept 2013

18. DRG: Disease Related Groups. http://www.gyogyinfok.hu/ magyar/hbcs_konyv.html (2011). Accessed 1 Sept 2013

19. Centre for Budapest Transport. http://www.bkk.hu/en/prices/ (2012). Accessed 1 Sept 2013

20. Debrecen Transport Services Closed Corporation. http://www. dkv.hu/en/fares (2012). Accessed 1 Sept 2013

21. Ministry of Health-National Health Insurance Fund's prospectus of the monthly payment of financing of curative and preventing care. In. (2012)

22. Koopmanschap, M.A., Rutten, F.F.: A practical guide for calculating indirect costs of disease. Pharmacoeconomics 10(5), 460-466 (1996)

23. Koopmanschap, M.A., Rutten, F.F., van Ineveld, B.M., van Roijen, L.: The friction cost method for measuring indirect costs of disease. J. Health Econ. 14(2), 171-189 (1995)

24. Laki, J., Monok, G., Palosi, M., Gajdacsi, J.Z.: Economical aspect of biological therapy in inflammatory conditions in Hungary. Expert Opin. Biol. Ther. 13(3), 327-337 (2013). doi:10.1517/ 14712598.2013.735654

25. Szende, A., Nemeth, R.: Health-related quality of life of the Hungarian population. Orv. Hetil. 144(34), 1667-1674 (2003)

26. Ciocon, D.H., Horn, E.J., Kimball, A.B.: Quality of life and treatment satisfaction among patients with psoriasis and psoriatic arthritis and patients with psoriasis only: results of the 2005 Spring US National Psoriasis Foundation Survey. Am. J. Clin. Dermatol. 9(2), 111-117 (2008)

27. Brodszky, V., Balint, P., Geher, P., Hodinka, L., Horvath, G., Koo, E., Pentek, M., Polgar, A., Sesztak, M., Szanto, S.,
Ujfalussy, I., Gulacsi, L.: Disease burden of psoriatic arthritis compared to rheumatoid arthritis, Hungarian experiment. Rheumatol. Int. 30(2), 199-205 (2009). doi:10.1007/s00296-009-09361

28. Fonia, A., Jackson, K., Lereun, C., Grant, D.M., Barker, J.N., Smith, C.H.: A retrospective cohort study of the impact of biologic therapy initiation on medical resource use and costs in patients with moderate to severe psoriasis. Br. J. Dermatol 163(4), 807-816 (2010). doi:10.1111/j.1365-2133.2010.09944.x

29. Driessen, R.J., Bisschops, L.A., Adang, E.M., Evers, A.W., Van De Kerkhof, P.C., De Jong, E.M.: The economic impact of highneed psoriasis in daily clinical practice before and after the introduction of biologics. Br. J. Dermatol. 162(6), 1324-1329 (2010). doi:10.1111/j.1365-2133.2010.09693.x

30. Kimball, A.B., Guerin, A., Tsaneva, M., Yu, A.P., Wu, E.Q., Gupta, S.R., Bao, Y., Mulani, P.M.: Economic burden of comorbidities in patients with psoriasis is substantial. J. Eur. Acad. Dermatol. Venereol. 25(2), 157-163 (2011). doi:10.1111/j. 1468-3083.2010.03730.x

31. Gleason, P.P., Alexander, G.C., Starner, C.I., Ritter, S.T., Van Houten, H.K., Gunderson, B.W., Shah, N.D.: Health plan utilization and costs of specialty drugs within 4 chronic conditions. J. Manag. Care Pharm. 19(7), 542-548 (2013)

32. Le Moigne, M., Sommet, A., Lapeyre-Mestre, M., Bourrel, R., Molinier, L., Paul, C., Montastruc, J.L.: Healthcare cost impact of biological drugs compared with traditional systemic treatments in psoriasis: a cohort analysis in the French insurance database. J. Eur. Acad. Dermatol. Venereol. (2013). doi:10.1111/jdv.12318

33. Levy, A.R., Davie, A.M., Brazier, N.C., Jivraj, F., Albrecht, L.E., Gratton, D., Lynde, C.W.: Economic burden of moderate to severe plaque psoriasis in Canada. Int. J. Dermatol. 51(12), 1432-1440 (2012). doi:10.1111/j.1365-4632.2011.05359.x

34. Ghatnekar, O., Ljungberg, A., Wirestrand, L.E., Svensson, A.: Costs and quality of life for psoriatic patients at different degrees of severity in southern Sweden - a cross-sectional study. Eur. J. Dermatol. 22(2), 238-245 (2012). doi:10.1684/ejd.2011.1635

35. Tang, M.M., Chang, C.C., Chan, L.C., Heng, A.: Quality of life and cost of illness in patients with psoriasis in Malaysia: a multicenter study. Int. J. Dermatol. 52(3), 314-322 (2013). doi:10.1111/j.1365-4632.2011.05340.x

36. Steinke, S.I., Peitsch, W.K., Ludwig, A., Goebeler, M.: Cost-ofillness in psoriasis: comparing inpatient and outpatient therapy. PLoS ONE 8(10), e78152 (2013). doi:10.1371/journal.pone. 0078152PONE-D-13-23199

\begin{tabular}{|l|lll|}
\hline Journal : Large 10198 & Dispatch : $\mathbf{1 0 - 5 - 2 0 1 4}$ & Pages : 9 \\
Article No. : $\mathbf{5 9 9}$ & $\square$ LE & $\square$ TYPESET \\
& MS Code : Supplement14_Paper11 & $\sim_{\mathrm{CP}}$ & $\checkmark$ DISK \\
\hline
\end{tabular}

